Athens Journal of Mass Media and Communications

Volume 8, Issue 2, April 2022 - Pages 131-144

\title{
Students' Social Apathy in Real and Virtual Worlds: A Comparative Study
}

\author{
By Seyed Kamaleddin Mousavi ${ }^{*} \&$ Marzieh Ahmadi Milasi ${ }^{ \pm}$
}

In recent years, social apathy has been able to attract the attention of sociologists and social psychologists. Thus, the present study addresses the issue of social apathy in the real and virtual worlds. This research, which consists of a social survey, was conducted in spring 2019 in Kashan, among which 384 students of Payame Noor University, Medical Sciences University, and the State University of Kashan, were selected via a non-proportional classified sampling method. The results showed that, in general, the degree of social apathy of students in both real and virtual environments is a little more than the middle, although its amount in the real spaces is slightly higher than virtual ones. It also became clear that there is a correlation between the degree of social apathy of students in the real world and the virtual worlds, but the degree of this apathy in the real or virtual world did not differ significantly in terms of the field of study, type of university, residence and income. In other words, the degree of social apathy was relatively the same in all the mentioned groups of students.

Keywords: social apathy, virtual world, students, information-communication technology

\section{Introduction}

Apathy is a concept of neglect and carelessness toward laws, norms or social and political events, although in some sociological definitions, it is considered as an opposition to the concept of altruism, and some others contrast it with participation and "social involvement" (Kalantari et al., 2007). In another look, apathy means isolation and lack of participation as expected. Some indicators of this participation are motivation to attend elections and voting, taking on party and popular positions, joining parties, organizations, clubs and various socio-political groups. Apathy appears in many forms, among which social apathy is one of the undesirable features of modern culture, manifesting by overemphasis on personal preferences and individualistic interests in urban life. Operating as an obstacle in the way of establishing positive social relations and participation, apathy weakens or even stops the process of national development (Sanatkhah and Akbarzadeh, 2017). From this point of view, Mohseni Tabrizi and Sedaghatifard (2011) have considered apathy as an expression of numbness, pessimism, reluctance and a kind of social depression. Apathy is a state or situation in which people consciously, cognitively, emotionally and critically react to social, political, and cultural issues in their orientations (Zahirinia et al., 2014).

\footnotetext{
*Assistant Professor, University of Kashan, Iran.

${ }^{ \pm}$Researcher, Isfahan University, Iran.
} 
It seems that over time, as societies become more complex and advanced, human beings lose their freedoms more than ever before. Society becomes stronger, but man becomes weaker i.e., human beings become more and more entangled in the bondage of modernity and its environmental coercive system. That is why, throughout history, the cry of regret and lamentation of philosophers, mystics, writers and thinkers has always been loud, and all of them consider returning to themselves and nature as the only way to release human beings from captivity and achieve true and perfect freedom (Mousavi and Haidarpour, 2011, p. 32). Social developments of the contemporary period have created a context in which only economic and livelihood concerns can keep human beings together for a while. Hence, some key sources of thought of the modern age such as secularism, individualism and humanism emerge and encourage modern man to ignore the world around him and to deal with their own self. In such a situation, there is no longer a specific justification for altruistic and committed social activities. The behavior of modern man has been affected by many social aspects, especially the development of individualism in the contemporary world, which has contributed to the problem of social apathy (Mirzapuri, 2016, pp. 61-62).

Social apathy makes people consciously become disinterested and careless to altruistic contributions, social responsibilities or other civic actions in terms of attitudes and behavior. In this regard, social apathy can be divided into two dimensions: altruistic and civic. Altruistic apathy means to be disinterested in, and disregard participatory actions and instead prefer self-interest over the interests of others; people in this situation avoid activities that bring more benefit for others and less for themselves. Civil apathy means to be disinterested in, or have disregard for social actions related to the formation of civil society; avoidance from a set of activities based on public interests in the context of civil society, whose benefits are indirect and eventually come back to the people themselves (Nawabakhsh and Mirzapouri, 2015).

Analyzing the problem, sociologists usually refer to social factors influencing social apathy, concentrating on values, norms, institutions, roles, social structure, stratification of society, socio-economic statuses, ethnicity, etc. while psychologists insist on individual factors like: motivation, personal capabilities, self-esteem, sense of confidence, sense of impact, sense of efficiency, and so on. In analyzing apathy, economists also pay attention to the conditions and capacities of society or individual (at macro and micro levels), concentrating on economic behaviors of individuals. But political thinkers usually pay attention to the form of government, the construction of power, power distribution mechanism, presence or absence of the of democracy, oppositions, parties, political groups, etc. as contributing factors (Anbari and Gholamian, 2016).

As we know, the main mission of sociology is to scientifically study social issues and problems and provide solutions to solve them. This mission is more important in the case of Iranian society, which is going through a period of transition from a traditional to a modern era. Entering various elements of modern culture has led to fundamental changes in the material and immaterial dimensions of Iranian culture. The scope and depth of these changes are so great that some Iranian sociologists are speaking about some kind of anomic and socially unhealthy 
conditions in the country (Chalabi, 1996; Rafipour, 1999). That is, a situation in which, according to Durkheim, previous social norms and ethical guidelines no longer have the necessary efficiency to guide social behaviors, but they have not yet been replaced by new effective norms. Obviously, in such circumstances, social relations are damaged and thus, the social indifference is seen everywhere (Mohseni Tabrizi and Sedaghatifard, 2011, p. 2). Undoubtedly, the basic and necessary conditions for development of a society are: building warm relations, improving social cohesion, social participation and mutual trust between individual, society, government, by which social apathy decreases. Unfortunately, paying attention to this issue is ignored in societies like Iran, so we observe an excessive increase in social apathy through the country which may lead to social rupture and collapse (Anbari and Gholamian, 2016).

Returning to the past, Iran's historical experience of the last four decades shows that the participation of the people has been one of the important factors that helped to lead to the victory of the 1979 Islamic Revolution and the resistance during an eight-year imposed war against Saddam Hussein. However, a brief look at the post-revolutionary referendums to date clearly shows the growing trend of social and political apathy among a significant portion of Iranians. For example, in the 2001 election almost 30 percent of eligible voters did not participate. By the 2020 parliament election, the rate increased to almost 60 percent. Moreover, the role of the working class in the victory of the 1979 revolution was so significant that some scholars such as Abrahamian (1998) considers the entry of this class into the arena of the revolution, and especially the strikes of the workers as the key cause of its victory. However, in recent years, even in the case of workers, there has been talk of worker's apathy in socio-political activities, so far that researchers have focused on exploring the reasons for this vast apathy among workers (Habibzadeh, 2005). The same trend is seen lastly among other social groups such as women, clerks, traders etc. The results of a national survey conducted in the country shows that the majority of respondents (more than $75 \%$ ) have actually little participation in organizations, institutions or civil associations. This fact indicates the existence of a kind of social apathy on a large scale (Shakoori, 2005).

Thus, apathy, as a social issue, is not only the result of various factors, but it also impacts the formation of social trends too. Occasionally, in scientific and academic settings, it seems to be of great importance and necessity because it brings various benefits and results. The results of such research can bring theoretical and practical benefits both at the middle and macro levels of society. For example, formal and responsible institutions can identify cases and examples of social apathy at the university level, and reconsider their strategies, decisions and plans. Low and weak presence of students in the elections of trade union councils and scientific associations, lack of attention and lack of compassion of some officials and professors towards students and their scientific achievements, lack of attention to research activities in the university teachers and students in the classroom, students being deprived of the minimum facilities for scholarships and dormitories, discrimination and injustice behavior of some professors in scientific evaluation of students educational activities, etc. are among the things that can lead to the growth of social apathy. Taking advantage of more accurate documentations 
or statistics, investigation of various dimensions of the issue may change the view of students and professors so far that they feel the dangers of such a phenomenon. On the contrary, failure to address the problem may lead students to think that they are not valuable to their university or society, and as a result, they feel abandoned and disappointed, and may become indifferent about their duties and responsibilities in university and society. If social apathy covers the human consciousness of students who are the future builders of society, the loss of social order and cohesion will appear on the horizon, and social problems can occur in a way that cannot be compensated easily.

Therefore, universities, as the most important educational arena, which train efficient human resources for society development, have not been an exception to this phenomenon. In recent years, stagnation and socio-political apathy in universities has become so increasing that the scientific, social and political atmosphere of the past times is no longer felt. While two decades ago the role of Iranian students in social and political events was much more prominent, nowadays, some studies show that a breeze of apathy is blowing among students. According to the mentioned studies, some variables impacting this situation are: securitization of university atmosphere, offensive behaviors of security guards of universities and semi-militant groups against student's demands or critics, fear of students from consequences of expressing their critiques on socio-political issues, growth of disappointment about their future, vast individualization because of the feeling of powerlessness to impact these affairs (Mohseni Tabrizi and Sedaghatifard, 2011).

At the same time, we know that the university is the atmosphere in which the Internet and cyberspace play an important role in the lives of students because they are involved in it since entering the university. By online registration and choosing course units, getting acquainted with study conditions and regulations, communication with professors and classmates, formation of telegram or WhatsApp groups and other online activities, they are dragged into cyberspace very fast, so the Internet penetrates their daily lives and becomes very important for them (Babaei Fard and Sharghi, 2014). Today, the design of many ideas, opinions, and non-academic interactions of students has also flowed in the Internet environments and promises to shape a second virtual life for students. These days, students' lives flow simultaneously in real and virtual spaces, and, in each of the two, they find a special atmosphere and feel special demands or needs. In this regard, social media facilitates waves of similarly condensed and empowered ideas by the rapid and widespread dissemination of information on the Internet. Since the interactive platform of social media reduces barriers to the social exchange of ideas, it becomes an effective tool for the participation of countless people in the current issues of society. In this way, we can ensure that the culture of participation lies in the context of social media (Hwang and Kim, 2015). The growth and development of the Internet, especially the virtual world, which keeps millions of people connecting and interacting with each other, is rapidly developing and flourishing these days, and many real-world phenomena have eventually opened their way into the virtual world. 
The question that arises here is, whether students as the most active internet users, have also fallen into a socio-political apathy in cyberspace or not. In other word, are students experiencing the same apathy in cyberspace as in the real academic environments? Or they are active in online social participations and responsibilities? Does the apathy of students in real environments penetrate to the virtual ones? The investigation of such phenomenon is the main concern of the study, so we try to explore the possible relationship between the degree of social apathy of students in real and virtual spaces.

In recent years, various studies have been conducted in Iran on social apathy. For example, Masoudnia (2001) points out that although social apathy is not a new phenomenon, it seems to have increased significantly with the social, political and economic developments of the Iranian society. Kalantari et al. (2007) have also conducted a study in which they draw some factors impacting on social apathy. The results show that the increase of empathy, acceptance of responsibility, and reduction of the cost of material rewards in relations between citizens can improve altruism and reduce social apathy. Also, Mohseni Tabrizi and Sedaghatifard (2011) pointed out that social apathy in Tehran is above average, and the five variables like: civic commitment, individualism, abnormalities, social satisfaction, and relative deprivation have affected it. Nabavi et al. (2014) have shown that socio-economic status, feelings of alienation, feelings of empathy, feelings of insecurity, and a person's capitals have affected citizens' apathy. Finally, Ghazizadeh and Kianpour (2015) concluded that the average score of social apathy among students is equal to 1.9 out of 5 , which indicates that social apathy is low and does not pose a threat to society in the short term, but it does not mean neglecting the issue for the future. Obviously, up today, most of the research conducted in Iran have mainly focused on the issue of social apathy in real environments and factors impacting on it, but there has been no investigation to deal with social apathy in cyberspace or comparing of it between real and virtual worlds. These research shortages increase the importance of doing such a study in order to clarify the degree of social apathy in two parallel environments, feeling the whole of the student's life.

\section{Theoretical Review}

One of the first pioneers to address the problems of modern man in industrial society is George Simmel. In his important article, The Metropolis and Mental Life, Simmel describes the problem of primitive man as not overcoming nature, but the problem of modern man as contrasting with the cultural products he had created. In his view, rationalization is a feature of life in urban environments, and a metropolis is essentially a monetary economic hub that is closely related to realistic tendencies based on the calculation of phenomena. A person who resorts to reason also develops a kind of apathy to phenomena, and interferes less in personal and emotional relationships. The result of living in a situation where innumerable stimuli constantly affect the human nerves is a kind of boredom or a state of apathy that occurs when a person's nerves are so attacked by contradictory 
stimuli. The nature of boredom is an indifference towards the distinction of things, in a way that one sees not the differences in phenomena, but the difference between them becomes unimportant to him. In other words, everything is seen on a gray surface of the same shape, with no priority given to any of them. This mentality is formed in the context of a monetary economy in which money enters all aspects of life and all differences are measured by money. From this perspective, the urban person deals with many people during the day, which is not comparable to the number of people a villager sees per day, where he is alone, isolated and has few acquaintances. An urban dweller is indifferent and alien to the world around him, hence the distance and separation is one of the dimensions of socialization in the city.

According to some contemporary sociologists and social psychologists, the human structure of urban life which contains large population, complexity of social relations, rationality in relationships, and so on, is considered as an important factor to increase social apathy among citizens. In this regard, results of the study of Amato (1983) in several cities showed that as the number in population increases, social structures and relations become more complex, people tend to be less altruistic, and thus their apathy increases (Olyansab Sharbiani, 2016, pp. 3840).

In Marxist tradition, the analysis of social apathy is the same as social alienation. According to this approach, the dominance of rationality based on cost/ benefit calculation in modern industrial societies encourages individuals to compete or conflict with each other in the context of production's relations, and the prevalence of such a phenomenon in any society intensifies individualism and alienation of people from each other (Mirzapouri, 2016, p. 104). Of course, when individualism and utilitarianism are preferred to collective interests in a society, both alienation and social apathy spread throughout social life. Some neo-Marxists also see new cities as tools of capitalist domination, and this kind of attitude can be seen in the views of Eric Fromm and Herbert Marcuse. They believe that the conditions of capitalism destroy the individual personality and hinder strong social and environmental ties, and it is suitable for the growth of apathy and alienation. Class consciousness in urban society disappears or weakens, so, the instrumental wisdom leaves no room for true wisdom (Olyansab Sharbiani, 2016, pp. 32-31).

Nowadays, cities have changed a lot and have become the main territory of information and communication technologies. In explaining the new situation, several theories point to the role of new media, especially the role of the Internet, and the virtual world in activating human connections, pulling people out of their locks, and placing them in the core of social interactions. For example, Wellman (2001) believes that the Internet not only provides the opportunity to contact friends and relatives with a low cost, but also creates networks containing face-toface communication with individuals and organizational partnerships to increase inside society. Wellman emphasizes that the Internet with its facilities and equipment, helps people to find the people and groups, join them, and participate in their programs and activities (Wellman, 2001, p. 438). In this compensatory and complementary view to the virtual world, it seems that the apathy and social isolation in the real world can be reduced through the Internet and cyberspace. 
Meanwhile, some theories of the Internet and the virtual world insist that what is happening in cyberspace and social networks is not separate from the realities of external society, but is a reflection of what is happening in real life. According to Nood and Attema (2006), in the virtual world exists the same things as in the real world because the real and virtual worlds are becoming more and more intertwined and are moving more towards unification. Citing numerous studies, they insist on a correlation between the situation of people in the real and virtual world; those who are more successful in the real world are mostly of the same group that is successful in the virtual world, where they act more and feel more satisfaction in both worlds. Even the number of friends a person has in the real world strongly correlates with the number of friends they have in cyberspace (Hadadi, 2011, p. 73). In the same vein, Slater's et al. (2006) research has shown that most of people's activities in cyberspace are consistent with their actions and choices in the real world. Rheingold (2002) also emphasizes that people in virtual communities usually do what they do in real life, although in real life people are more responsible for their own behaviors. In other words, in cyberspace, many things can happen by the same way as in the real world (Rheingold, 2002, p. 71).

According to the brief explanations provided here, it is possible to assume a reflection theory - mentioned by Attema, Nood, Rheingold, and others - when social apathy of a student appears at the same level in real and virtual spaces. But if the social apathy in cyberspace will be less than the real space, the compensatory and complementary theories - pointed out by Wellman - are approved here. In order to analyze the issue, some research hypotheses were determined as follows:

Hypothesis 1: Level of social apathy in real space is higher than in virtual space.

Hypothesis 2: There is a relationship between social apathy in real and virtual worlds. Hypothesis 3: There is a relationship between the mental apathy in the real and virtual worlds.

Hypothesis 4: There is a relationship between the practice of apathy in the real and virtual worlds.

Hypothesis 5: The degree of apathy among students varies according to gender, age, and income and other demographic informations. etc.

\section{Methods}

Social apathy is a situation in which people consciously become disinterested and careless to altruistic contributions, social responsibilities and other civic actions. In this study the concept social apathy was measured by the consideration of its two dimensions: mental (attitude) and practical (behavioral) as described in Table 1. 
Table 1. Dimensions and Indicators of Social Apathy

\begin{tabular}{|c|c|c|}
\hline Variable & Dimensions & Indicators \\
\hline $\begin{array}{l}\text { Mental } \\
\text { Social Apathy }\end{array}$ & $\begin{array}{c}\text { Attitudes } \\
\& \\
\text { Points of view }\end{array}$ & $\begin{array}{l}\text { Disappointment about effectiveness } \\
\text { Distrust of cooperation and participation } \\
\text { Ignoring news and events } \\
\text { Disinterest in social activity } \\
\text { Fear of giving comment at events }\end{array}$ \\
\hline $\begin{array}{l}\text { Practical } \\
\text { Social Apathy }\end{array}$ & $\begin{array}{c}\text { Behaviors } \\
\& \\
\text { Activities }\end{array}$ & $\begin{array}{l}\text { Experience the fruitlessness of efforts } \\
\text { Poor follow-up on the situation of } \\
\text { compatriots } \\
\text { No participation or support of social } \\
\text { campaigns } \\
\text { Submit comments and critiques only among } \\
\text { friends } \\
\text { No reaction to government decisions } \\
\text { Refrain from commenting on socio-political } \\
\text { issues }\end{array}$ \\
\hline
\end{tabular}

Like most social studies, a survey method has been used in this study. The statistical population of the research included 13,202 students in the academic year 2018-2019 studying in three public universities in Kashan city; 8,159 from Kashan State University, 2,943 from University of Medical Sciences, and 2,100 from Payame Noor University. To determine the sample size, we used Cochran's formula by which the sample size was calculated as follows:

$$
n=\frac{\mathrm{Nt}^{2} \cdot \mathrm{pq}}{\mathrm{Nd}^{2}+\mathrm{t}^{2} \mathrm{pq}} \quad n=\frac{3720 \times 3 / 8416 \times 0 / 25}{13202 \times 0 / 0025+3 / 8416 \times 0 / 25}=348
$$

According to the purpose of the research and the characteristics of the statistical population, the classified sampling method has been used. Data gathering was conducted via a questionnaire consisting of 37 questions inspired by the research book Social Apathy in Iran written by Mirzapouri (2016), and the questionnaire, Scales for Social Capital in an Online Era by Williams (2006) with a slight change in order to be adjusted to the target population sample. After compiling the initial questionnaire, the final questionnaire was prepared by performing a pre-test on a number of students and eliminating possible problems and ambiguities. In order to measure the reliability of the research variables and evaluate the main subscales in the questionnaire, a preliminary test was performed among 30 persons; data of which were measured by Cronbach's alpha test to determine the internal consistency of the items in each variable. Table 2 shows the alpha coefficients of the variables.

Table 2. Cronbach's Alpha Coefficients for the Main Research Variables

\begin{tabular}{|l|c|c|}
\hline Variables & Number of Items & Alpha coefficient \\
\hline Social apathy (in general) & 30 & 0.83 \\
\hline Mental/attitude dimension of social apathy & 14 & 0.75 \\
\hline Practical/behavior dimension of social apathy & 16 & 0.65 \\
\hline
\end{tabular}




\section{Results}

Among the surveyed students, $46.6 \%$ were men and $53.4 \%$ were women. The minimum age of the respondents was 17 while the maximum is 47 years, and the total average age of the respondents was 21.6 years. Respondents reported that $90.6 \%$ were single and $9.4 \%$ were married. At the time of the research, $84.3 \%$ of respondents were studying study in their bachelor degree, $7 \%$ in their postgraduate degree and $6.3 \%$ at the Ph.D. level. Almost $20 \%$ of students were studying in engineering fields, $22.7 \%$ in medical sciences, $28.8 \%$ study humanities, $13.0 \%$ in the arts and finally $15.6 \%$ studied in basic sciences. Regarding their university enrollment, $17.0 \%$ of the respondents were from Payame Noor University, 59.8\% from Kashan State University, and 23.2\% from the University of Medical Sciences. In terms of place of residence, $41.4 \%$ live in Kashan, $54.4 \%$ in other cities, and $3.9 \%$ in rural areas. In general, the degree of social apathy among the respondents is slightly above average, indicating a relative penetration of the problem among students in the city of Kashan, which is known as a religious and traditional part of the country in Iran. While the rate of the experienced apathy among students here is not yet at a crisis level, it has the potential to increase because of the unpredictable social, political and economic situations of the country; a phenomenon which imposes a vast threat of unemployment on university graduates in Iran. Nowadays, faced with so many political and ideological pressures, students are worried about their employment, marriage, the high cost of living in the cities, etc. These circumstances decrease student's selfsufficiency and make them feel more disappointed, alienated and apathetic. The experience of social empathy by students runs both in their real and virtual lives and in their attitudes and behaviors, but the rates of apathy are not the same. In order to better understand the situation, the average scores of social apathy in the real/virtual spaces, as well as in the mental/practical dimensions were tested by one-sample T-tests, the results of which are presented in Table 3.

Table 3. Results of One-Sample T-Test about Social Apathy

\begin{tabular}{|l|c|c|c|}
\hline Variables & $\begin{array}{c}\text { Test } \\
\text { average }\end{array}$ & $\begin{array}{c}\text { Observed } \\
\text { average }\end{array}$ & Sig. \\
\hline General social apathy in real spaces & 45 & 47.3 & 0.000 \\
\hline General social apathy in virtual spaces & 45 & 46.8 & 0.000 \\
\hline Mental dimension of apathy in real spaces & 21 & 25 & 0.000 \\
\hline Mental dimension of apathy in virtual spaces & 21 & 22.2 & 0.000 \\
\hline Behavioral dimension of apathy in real spaces & 21 & 24.4 & 0.006 \\
\hline Behavioral dimension of apathy in virtual spaces & 21 & 22.3 & 0.000 \\
\hline
\end{tabular}

Table 3 shows averages of the students' social apathy in the real and virtual spaces in general, and according to its mental or practical dimensions. Comparing the observed and test average scores shows that in all cases, the levels of social apathy in real and virtual spaces are above test average - a fact that indicates a relatively problematic amount of social apathy among students. Moreover, the comparison of the observed averages shows that both in mental and behavioral dimensions, the rate of students' apathy in the real world $(m=25,24)$ is higher than 
their level of apathy in the virtual spaces $(m=22,22)$. Affirming the first of the hypotheses of the research, this result shows that students in cyberspaces experience lower level of social apathy than in real environments; this lower degree of apathy is observed both in their attitudes and behaviors. Moreover, analyzing the status-quo of the country, students are mentally more alienated and unmotivated to do anything in real life versus in virtual spaces. The level of mental apathy is obviously higher than online environments which are yet to be considered in Iran as the basic anchor of civil activities and social participations.

In order to analyze the other research hypotheses and to measure the possible relationships between students' apathy in real and virtual spaces to further give a glimpse on the factors affecting this apathy, a correlation test was used. First, the relationship between social apathy in general, and also in terms of attitudes and behavior dimensions, was measured via the Pearson correlation test; the results of which are reflected in Table 4.

Table 4. Correlation Test Results on Social Apathy in Real and Virtual Environments

\begin{tabular}{|l|c|c|}
\hline Variables & $\mathbf{N}$ & Correlation coefficient \\
\hline $\begin{array}{l}\text { Degree of social apathy in real \& cyber } \\
\text { environments }\end{array}$ & 351 & $\mathbf{0 . 4 5 6} * *$ \\
\hline $\begin{array}{l}\text { Degree of mental apathy in real \& cyber } \\
\text { environments }\end{array}$ & 368 & $\mathbf{0 . 4 3 7} * *$ \\
\hline $\begin{array}{l}\text { Degree of behavioral apathy in real \& cyber } \\
\text { environments }\end{array}$ & 368 & $\mathbf{0 . 4 5 8} * *$ \\
\hline
\end{tabular}

Results in Table 4 show that there are relationships - in general, mental and behavioral dimensions - between the degree of students' apathy in real and virtual environments. The existing relationship means that any increase of students' apathy in real environments leads to an increase of apathy in cyberspaces, and vice versa. This result affirms the second, third and fourth hypotheses of the research and supports a reciprocal influence between students' apathy in their real and virtual lives. Finally, the results of $\mathrm{T}$ and ANOVA tests between demographic variables (gender, age, marital status, etc.) gauging the level of apathy of students in real and virtual spaces show no significant differences ( $P$ values $>0.05$ ); a fact that indicates that all sex, age, income, specialty groups of students experience a relatively similar level of social apathy. This result does not prove the last or $5^{\text {th }}$ hypothesis of the present research.

\section{Conclusion}

The main subject of this study was the comparison of students' indifference in real and virtual worlds - a phenomenon that includes mental (attitudinal) and practical (behavioral) dimensions. In this regard, the opinions of experts such as Wellman, Rheingold, Nood and Attema have been used.

Nowadays, many believe that indifference, as a social issue which is made of various variables and historical, cultural, political, social and psychological 
contexts, has somehow affected all societies at different levels and fields. But since the basis of the formation and development of a society is based on the active presence of its members in the social arena, any indifference will disrupt the process of development and overall social health (Mirzapuri, 2015, pp. 192-193). In this regard, social apathy is known as a kind of social disease while social attention, participation and altruism in social life is a sign of active dynamism and social health (Zahirinia et al., 2014). In addition, apathy presents a version of protest, which shows its opposition to the current social order and becomes a response to alienation from the social system. In fact, due to the alienation from the social system, apathy causes a gap in social structures, keeping individuals away from ongoing social processes. People who do not participate in their society, apparently suffer from social apathy, and not paying enough attention to this issue will produce hazardous results in different aspects of societal life. On the other hand, today, the use of technology has become an integral part of everyday life. The Internet as a social media can play a key role in directing peoples' attitudes and social actions, but we should know that people do not treat in their interaction with this media passively. They think and interpret messages and then take action, and this action can lead to the creation of new social structures. Students are the most intelligent, active part of societies, and universities - the most important educational institution and a place for training efficient human resources, and for strengthening the culture of cooperation and participation. Thus, the signs of apathy in academic settings should be taken seriously, because it harms the positive role of students in promoting the mental health of society. Considering the importance of the concept of the virtual world as a new space for human interaction and social indifference as a special quality in social interaction between humans, this study sought to measure social indifference, especially among students, in the real world and virtual world.

The hypotheses presented in this study-except for those related to demographic variables - were all confirmed by the Pearson correlation test. According to the results of T-test, the degree of social apathy among male and female students (both in the real and in the virtual spaces) did not show a significant difference, i.e., due to the closeness of the means of these two groups, girls and boys feel a similar degree of apathy. Also, in terms of marital status of students, it became clear that the degree of social apathy between single and married students did not show a significant difference. Considering students' educational levels, fields of study, university, income and residence, the ANOVA test showed that different levels of education, fields of study, universities, different places of residence and different incomes - in real or virtual environments - have no significant difference in the degree of students' social apathy. In all mentioned groups, students are experiencing the same degree of apathy.

The results of this study illustrates that the average scores of students' social apathy in both real and the virtual spaces are above average, although in real space this apathy seems to be higher than in cyberspace. In other words, students feel indifferent about news, events and/or government decisions in Iran, but this feeling is higher in real environments than in virtual ones. According to the results, the mental/attitudinal dimension of social apathy among students is at a moderate 
level, but in real spaces it is more than in cyberspace. The relative closeness of the average apathy scores in the real and virtual spaces is reminiscent of the theories of Rheingold, Nood, Attema, and researchers who view cyberspace as reflecting realworld events in a way that the pulse of both worlds hits similarly. In other words, if the severity of social apathy of students is moderate, they are showing the same degree of apathy to social issues in cyberspace. This apathy, firstly, is formed in their attitudes and mentalities for some reasons declared by them, such as: students' frustration with their effectiveness, lack of trust in cooperation and partnership with others, disregard for news and events, disinterest in social activity, and/or fear of commenting on events because of its potential consequences. Such attitudes among students affected on their practical apathy, led to behaviors such as: poor follow-up of the situation of compatriots, lack of support and active participation in social campaigns, presenting opinions and criticisms only among friends, no reactions to government decisions and refraining from expressing socio-political comments, etc.The fact that the average score of apathy in real space - both attitudes and behaviors - is higher than the average score of apathy in cyberspace, supports the role of cyberspace in compensating some shortages of virtual world, invoked by the opinions of Wellman and their co-thinkers. By more students engaging in cyberspace, the intensity of social apathy that they experience in real environments reduces and the situation slightly improves.

It is noteworthy that Kashan is a city of the Esfahan Province. It is a traditional city and much smaller than the city of Esfahan - the center of province. Comparing the results of this study with a study conducted by Ghazizadeh and Kianpour about social apathy among students of the University of Isfahan-where the average score of social apathy among students was 1.9 out of 5-shows that the situation of social apathy among students in Kashan is worse than that of students in Isfahan State University. The reasons about why, in a smaller and more traditional city like Kashan, the level of social apathy is higher than a metropolis like Esfahan belongs to some socio-cultural factors worthy of an independent study.

Finally, according to the results of this study, which shows the approximate similarity of social apathy among different groups of students, more attention to the capacity of the Internet is crucial in reducing the lack of motivation of young people. By using virtual environments, society can better benefit from the ideas and innovations of young people for its development, and accordingly, by developing associations or non-governmental organizations, and formulating social rules in accordance with civil society. Given the interdisciplinary nature of social apathy and the results it brings about, it has become deserved to examine the various branches of social sciences and humanities.

\section{References}

Abrahamian, Y. (1998). Iran between two revolutions: an introduction to the political sociology of contemporary Iran. Tehran: Ney Publishing. 
Amato, P. R. (1983) Helping behavior in urban and rural environments, field studies based on a taxonomic organization of helping episodes. Journal of Personality and Social Psychology, 45, 571-586.

Anbari, M., Gholamian, S. (2016). Sociological explanation of factors related to social apathy. Journal of Study of the Iranian Social Issues, 7(2), 133-159.

Babaei Fard, A., Sharghi, K. (2014). Internet, identity, and daily life of students of Payame Noor and Islamic Azad universities. Journal of the Institute for Humanities and Cultural Studies, 5(2), 1-36.

Chalabi, M. (1996). Sociology of order; theoretical description and analysis of social order. First Edition. Tehran: Ney Publishing.

Ghazizadeh, H, Kianpoor, M. (2015). Study of social apathy among students of the University of Isfahan. Journal of Strategic Researches on Security and Social Order, 4(1), 59-78.

Habibzadeh, A. (2005). Political apathy of workers and its effect on reducing their political participation in the Islamic Republic of Iran. Master Thesis. Islamic Azad University, Central Tehran Branch.

Hadadi, F. (2011). The study of the relationship between social capital in the virtual and real worlds. Master Thesis. Tehran: Shahed University.

Hwang, H., Ok Kim, K. (2015). Social media as a tool for social movements: the effect of social media use and social capital on intention to participate in social movements. International Journal of Consumer Studies 39(5), 478-488.

Kalantari, P., Adibi, M., Rabbani, R., Ahmadi, S. (2007). Study of apathy and altruism in Iranian urban society and the factors affecting it. Daneshvar Raftar Bi-Quarterly, Shahed University, 14(22), 2735.

Masoud nia, E. (2001). Sociological explanation of citizens' apathy in social and political life. Political Economic Information.

Mirzapuri, J. (2016). Social apathy in Iran. Qom: Zamzam-e Hedayat Publications.

Mohseni Tabrizi, A., Sedaghatifard, M. (2011) Research on social apathy in Iran. Journal of Applied Sociology, 22(3), 1-22.

Mousavi, S., Haidarpour M. (2011). The riddle of alienation in social thought. M.A. Dissertation. Tehran: Shahed University, Publishing Center.

Nabavi, A., Nawah, A., Amirshirzad, N. (2014). A study of factors affecting social apathy. Iranian Journal of Sociology, 15(3), 132-161.

Navabakhsh, M., Mirzapouri, J. (2015). Sociological analysis of anomaly on social apathy. Journal of Iranian Social Development Studies, 7(3), 53-67.

Nood, D., Attema, J. (2006). Second life: the second life of virtual reality. The Hague: Electronic Highway Platform - EPN.

Olyansab Sharbiani, S. E. (2016). Social apathy. Tabriz: Ons Publications.

Rafipour, F. (1999). Anomie or social chaos. Tehran: Soroush.

Rheingold, H. (2002). Smart mobs: the next social revolution. Cambridge, MA: Perseus Publishing.

Sanatkhah, A., Akbarzadeh, R. (2017). A study of the relationship between social apathy and apathy to addiction. Journal of Law Enforcement Science, 8(19), 24-44.

Shakoori, A. (2005). Supportive behaviors and the reasons for their occurrence. Social Welfare Quarterly, 5(18): 357-386.

Slater M. , Antley A., Davison A., Swapp D., Guger C., Barker, C., et al. (2006). A virtual reprise of the Stanly Milgram obedience experiments. PLos One, 1(1), e39.

Wellman, B. (2001). Physical place and cyber place: the rise of networked individualism. In L. Keeble, B. D. Loader (eds.), Community Informatics: Shaping ComputerMediated Social Relations. London: Rutledge. 
Williams, D. (2006). On and off the net: scales for social capital in an online era. Journal of Computer-Mediated Communication, 11(2), 593-628.

Zahirinia, M., Golabi, F., Ayuriq, R. (2014). Identifying the effective factors of social indifference among students of Mohaghegh Ardabili University. Iranian Social Sciences Studies, 12(45), 86-111. 